\title{
El magazine televisivo: equipos de trabajo como fórmula de innovación docente
}

\author{
Belén ANDUEZa LóPEZ \\ Universidad Nebrija, Madrid (España) \\ mandueza@nebrija.es \\ Julián NiETo REDRUEJO \\ Universidad Nebrija, Madrid (España) \\ juliannietoredruejo@gmail.com
}

\section{Resumen:}

En el máster Periodismo en televisión de la Universidad Nebrija hemos puesto en marcha una dinámica de trabajo basada en la creación de equipos de trabajo. Nos marcamos una serie de metas encaminadas a fortalecer la cooperación e interdependencia de los alumnos. Por ejemplo: solucionar problemas y realizar tomas de decisiones en tiempo limitado y con alta presión para alcanzar resultados, capacidad de trabajo en equipo y dominar con suficiencia la gestión de la diversidad, y un conocimiento profundo de las aplicaciones y recursos tecnológicos disponibles para crear, construir y analizar productos audiovisuales.

Palabras clave:

Máster, Nebrija, magazine, late night, televisión, trabajo en equipo, sinergia.

\section{The TV magazine: work teams as a teaching innovation formula}

\begin{abstract}
:
For the TV Journalism Master of Nebrija University, we have launched a workflow based on the creation of work teams. We set a series of goals aimed at strengthening cooperation and interdependence of students. For example, troubleshooting and decision-making with limited time and with a high pressure to achieve results; teamwork ability; sufficiency in dominating diversity management, and a thorough understanding of applications and technological resources available to create, construct and analyze audiovisual products.
\end{abstract}

\section{Key Words:}

Masters, Nebrija, magazine, late night, television, teamwork, synergy.

\section{Referencia normalizada:}

Andueza López, B. y Nieto Redruego, J. (2013) El magazine televisivo: equipos de trabajo como fórmula de innovación docente. Historia y Comunicación Social. Vol. 18. № Especial Noviembre. Págs. $573-585$.

Sumario: 1. Introducción, 2. Metodología, 3. La puesta en marcha, 4. Los equipos, 5. La opinión de los alumnos, 6. Conclusiones, 7. Bibliografía 


\section{Introducción}

La actividad docente dentro de los Masters de Periodismo en Televisión de la Universidad Nebrija, apuesta por una mayor cercanía al medio, lo que supone una necesidad de creer en una docencia a través de profesionales inmersos en la creación de productos televisivos con amplia experiencia en diferentes ámbitos, y que combinen sus esfuerzos en la impartición de las asignaturas.

No se trataba solamente de coordinar trabajos independientes sino de generar la sinergia necesaria entre dos asignaturas (Narrativa Audiovisual y Espacios Informativos) para convertir a un grupo de personas, que nunca habían trabajado juntos, en un equipo de trabajo. De hecho, ninguno de los alumnos había participado en un proyecto similar, pero a cambio, contábamos con el interés y el entusiasmo de la mayor parte de ellos.

Para alcanzarlo nos marcamos una serie de metas encaminadas a fortalecer la cooperación e interdependencia de los alumnos, muy relacionados con las competencias generales y específicas que deben adquirir durante la realización del Máster de Periodismo en Televisión de nuestra Universidad. Por ejemplo: solucionar problemas y realizar tomas de decisiones en tiempo limitado y con alta presión para alcanzar resultados, capacidad de trabajo en equipo, dominar con suficiencia la gestión de la diversidad, o un conocimiento profundo de las aplicaciones y recursos tecnológicos disponibles para crear, construir y analizar productos audiovisuales.

Los alumnos se organizaron siguiendo el modelo de la redacción de un programa magazine. Se repartieron funciones específicas, con competencias cerradas, y marcando una serie de objetivos muy ambiciosos que podrían resumirse en dos: Enseñar a los alumnos como se realiza un magazine de televisión y a trabajar en equipo.

En una gran reunión de redacción, en la que participaron todos los alumnos, se procedió a planificar el trabajo en su conjunto, y elegir qué tipo de magazín querían poner en marcha. Después se formaron los grupos de trabajo y finalmente se marcaron los objetivos para cada uno de ellos. En concreto se crearon cuatro grupos: Realización y cámaras; Dirección y edición; Producción y Redacción.

Una vez perfilados dos programas pertenecientes al formato magazine, pero muy diferentes entre sí en cuanto a contenido y diseño, puesto que uno correspondía al magazine de mañana y el otro a un late-night, se llevó a la práctica su realización. En la asignatura de Narrativa Audiovisual comenzó el diseño de la imagen y el sonido, de la plástica televisiva. Los alumnos se enfrentaron a la dificultad de la organización del plató, de las diferentes funciones del control (sonido, mezclador, control de cámaras, realizador y ayudante de realización), de las funciones de plató (regidor, cámaras y producción), de adaptar los planos, el ritmo del programa y la ubicación de los diferentes sets al guion previamente diseñado. Todo ello con la dificultad añadida de llegar a hacerlo en riguroso directo, solventando obstáculos como movimientos de cámara, de invitados, pasos a publicidad, canciones en directo o entrevistas telefónicas. 
Una unión de esfuerzos cuyos resultados aportaron el cumplimiento de competencias propias del Máster y del trabajo periodístico en televisión, como son el trabajo en equipo, el reparto de funciones, la toma de decisiones, el desarrollo de las habilidades de aprendizaje y la obtención de un resultado del suficiente nivel profesional, que los alumnos pudieron mostrar a través de su televisión web donde trabajaban: Canal Nebrija. http://blogs.nebrija.es/canalnebrija/category/informativos/

Una vez establecidos los objetivos había que generar una estructura de liderazgo. Fue una tarea dirigida, en busca de ideas sobre cómo debía ser un magazine. Al cabo de una hora, todos los integrantes del equipo tenían claro quién debía liderar al grupo. Pero la dinámica interna funcionó de forma transversal. Las decisiones se tomaban de forma grupal por consenso, el grupo tenía personalidad propia.

Una vez que el plan estuvo establecido, lo importante fue mantenerlos a todos involucrados en un continuo flujo de información.

Lo que intentamos explicar en este trabajo es de qué manera el individuo se adapta al proceso que supone trabajar en equipo y cómo, a su vez, este propicia el desarrollo y el crecimiento personal y profesional de cada uno de sus integrantes.

Partiendo de esta base, e intentando formar a los alumnos en una de las competencias necesarias para su vida laboral, "que los alumnos tengan una gran capacidad de trabajo en equipo y dominen con suficiencia la gestión de la diversidad" (Cg7, Memoria Máster Periodismo en Televisión, 2013: 17), se les hizo ver a los alumnos que esta forma de trabajar suponía un gran número de ventajas y beneficios. A la vez que disminuye la carga de trabajo individual, se obtienen mejores resultados, se aprende a escuchar y a respetar a los demás, se pueden plantear objetivos mucho más ambiciosos, se alcanzan resultados mucho más satisfactorios y en último lugar, se puede decir que el trabajo en equipo favorece el crecimiento personal de los integrantes del equipo.

\section{Metodología}

En la elaboración de este trabajo hemos utilizado varias técnicas metodológicas. La principal, aplicada a lo largo de todo el ejercicio, ha estado inspirada en lo que podríamos definir como "técnica de grupos". Los grupos de discusión constituyen una técnica de recogida de información cuantitativa "destinada a inducir la producción del discurso espontáneo de sus participantes ante un conjunto de conceptos delimitados por el investigador o por la persona encargada de realizar el estudio". (De Miguel, 2005: 133)

Entre la amplia tipología de grupos, en esta ocasión hemos utilizado el denominado "torbellino de ideas o brainstorming", mediante el cual, un grupo de personas pone en común todas sus ideas en busca de las mejores soluciones a sus problemas.

También hemos utilizado la llamada "técnica interrogativa". Para profundizar en el trabajo en equipo diseñamos una técnica metodológica definida como "técnica interrogativa o de preguntas" tendente a establecer un cauce de comunicación en 
tres direcciones. Conductor-Equipo, Equipo-Conductor y Dentro del equipo. Con la aplicación de esta técnica pudimos conocer las experiencias de los integrantes del equipo y explorar sus conocimientos: facilitó el intercambio de opiniones, detectó la comprensión que se iba teniendo sobre el tema y nos permitió evaluar el logro de los objetivos.

Las ventajas que ofrece esta técnica basada en el intercambio constante de información, a través de preguntas y respuestas, son varias, pero destacamos el hecho de que planteando el trabajo así, se consigue atraer la atención de los individuos y se estimula en raciocinio haciéndoles comparar, relacionar, juzgar y apreciar críticamente sus respuestas a los problemas planteados; muy en la línea de la competencia general $\mathrm{n}^{\mathrm{o}} 4$ de la memoria del Master, donde se indica que los alumnos deben saber aplicar los conocimientos adquiridos y desarrollar una gran capacidad para solucionar problemas y realizar tomas de decisión relacionadas con el tratamiento periodístico de las noticias, así como en el Medio Televisión en condiciones de tiempo limitado y alta presión por alcanzar resultados.

Además, esta técnica permite ir evaluando, en cada sesión, si los objetivos fijados se van cumpliendo, propiciando una relación de mayor confianza entre los distintos individuos del equipo y de todos ellos con los directores del trabajo.

Por último se llevaron a cabo "estudios de casos" como tercera técnica de trabajo consistente en el relato de un problema o un caso práctico real incluyendo detalles suficientes para facilitar a los equipos el análisis.

Era el momento del estudio y análisis del género conocido como infoshow. El infoshow es, básicamente, un programa con entrevistas, charlas y conversaciones, llevada a cabo por un presentador "estrella". Suele estar complementado con otro tipo de atracciones como actuaciones musicales, concursos o la participación del público en el plató. Con el estudio de este tipo de programas perseguimos los siguientes objetivos: La aplicación de conocimientos teóricos de la disciplina estudiada en situaciones reales, el análisis de situaciones vividas por otros bajo sus aspectos positivos y negativos y, sobre todo, enseñar a los integrantes del equipo a formar juicios de valor y de realidad.

Consideramos que esta técnica aporta dos ventajas fundamentales: por un lado, crea una atmósfera propicia para intercambiar ideas y por otro, se relaciona a los alumnos con problemas de la vida real.

\section{La puesta en marcha}

Sin duda, el trabajo en equipo conlleva compartir información, estar abierto a discusiones, saber escuchar y ser receptivo a todas las ideas, ya sean buenas o malas. En definitiva, los profesores trabajamos sentando las bases necesarias para crear un ambiente participativo, en el que los alumnos puedan exponer libremente sus opinio- 
nes y sus ideas. Partiendo de la base de que para que un equipo funcione es esencial que haya armonía entre sus integrantes, intentamos que los equipos que se formasen fuesen lo más homogéneos posible, que dominase un ambiente de entendimiento personal y donde la comunicación fluyeses e forma natural. Fue entonces, cuando estuvimos en condiciones de poner en marcha la creación de equipos de trabajo. Los alumnos se organizaron siguiendo el modelo de la redacción de un programa magazine y se repartieron funciones específicas, con competencias cerradas.

Nos habíamos marcado una serie de objetivos muy ambiciosos, como ya se comentó en la introducción y que se resumieron en dos: Enseñar a los alumnos como se realiza un magazine de televisión y enseñar a los alumnos a trabajar en equipo.

En primer lugar, se les enseñó a seleccionar los temas susceptibles de formar parte de un magazine, elegir un formato, elaborar una escaleta adaptada a ese formato, crear las "piezas o vídeos" necesarios para elaborar un magazine, la puesta en escena, la confección de una agenda con la búsqueda de los protagonistas, la búsqueda de las opiniones de los especialistas y la retroalimentación e implicación del espectador.

Con respecto al segundo gran objetivo, el aprendizaje del trabajo en equipo, procedimos de la siguiente manera. En primer lugar, con todos los alumnos reunidos, en una sesión general de redacción se procedió a planificar el trabajo en su conjunto y elegir qué tipo de magazine querían poner en marcha. Después se formaron los grupos de trabajo y finalmente se marcaron los objetivos para cada uno de ellos. En la fijación de los objetivos individuales no participamos los profesores del curso, ésta fue una responsabilidad ya exclusiva de los alumnos.

Se crearon cuatro grupos de trabajo: realización y cámaras, dirección y edición, producción y cuarto grupo de redacción. Cada estudiante era responsable de su propio trabajo ante el resto de los integrantes de su grupo, ya que era fundamental para que el resto pudiera desarrollar el suyo.

Antes de empezar, los profesores implicados elaboramos, a modo de guion práctico, una serie de recomendaciones pensadas para los alumnos que tenían alguna responsabilidad de coordinación-dirección. Era una guía de buen funcionamiento para los jefes o líderes de grupo.

1. Elaborar una lista y distribuir las tareas propias y las ajenas.

2. Escribir qué hay que hacer para cubrir las funciones previstas y las responsabilidades que cada uno tiene.

3. Elaborar una serie de reglas básicas de trabajo del equipo que dirige y cómo coordinar los esfuerzos individuales.

4. Marcar una serie de normas simples y sencillas para el grupo que dirige. Por ejemplo: horario, asistencia a reuniones, puntualidad, cumplimiento en el trabajo, etc.

5. Para cumplir los objetivos y metas propuestos, se deben crear rutinas de trabajo adecuadas a la realidad del grupo, y estrategias útiles que ayuden a cumplir el plan previsto. 
Una vez distribuidas todas las funciones y hechas todas las recomendaciones, procedimos a perfilar dos programas pertenecientes al formato magazine, pero muy diferentes entre sí en cuanto a contenido y diseño, puesto que uno correspondía al magazine de mañana y el otro a un late-night.

Dentro de la asignatura de Narrativa Audiovisual comenzó el diseño de la imagen y el sonido, de la plástica televisiva y de la preparación para la realización en directo de los programas. Los alumnos tuvieron que hacer frente a la dificultad de la organización del plató, de las diferentes funciones del control (sonido, mezclador, control de cámaras, realizador y ayudante de realización), de las funciones de plató (regidor, cámaras y producción), de adaptar los planos, el ritmo del programa y la ubicación de los diferentes sets al guion previamente diseñado. Todo ello con la dificultad añadida de llegar a hacer en riguroso directo, solventando obstáculos como movimientos de cámara, de invitados, pasos a publicidad, canciones en directo entrevistas telefónicas.

\section{Los equipos}

Los integrantes de los equipos eran todos jóvenes, con una edad media de veinticuatro y veinticinco años. En principio, trabajar con personas de esta edad nos llevaba a presuponer que todo serían ventajas. Sin embargo, se presentaron algunos problemas del carácter propio de esta edad, principalmente de los líderes ya definidos dentro de cada grupo y que pretendían imponer sus propias ideas como verdaderas.

El Equipo 1 estaba formado por quince alumnos. Eligieron el formato de un magazine matinal, al que llamaron "Buenos días Nebrija". La mayoría de sus integrantes llegaba a este proyecto del master con muy poco o ninguna experiencia profesional previa en la televisión. Algunos de ellos, pocos, habían realizado prácticas en algún medio televisivo de carácter local o autonómico, dentro de las prácticas obligatorias de su grado en periodismo y/o comunicación, pero la mayoría no se había enfrentado con un puesto de trabajo en este medio audiovisual.

Este equipo optó por un formato clásico que la televisión generalista ha explotado con éxito de audiencia en su franja de la mañana. En este caso eligieron un modelo inspirado en el programa de Antena 3, Espejo Público. Se trataba, por lo tanto, de poner en marcha un programa definido en los manuales como un contenedor de contenidos dedicados a la información y el entretenimiento, con la finalidad de captar a una audiencia masiva. Una vez dado el visto bueno a la idea original, y antes de empezar a diseñar una estructura, se dedicó una sesión de tres horas a explicarles el origen y las características del infoshow. Se trataba de dotar a los alumnos de un conocimiento teórico previo, necesario para llevar a cabo una buena realización de su proyecto.

En una discusión general, en la que participaron en pie de igualdad todos los integrantes del equipo, decidieron dividir su programa en las siguientes secciones: 
1. Actualidad política, económica y social

2. Actualidad de sucesos

3. Actualidad de la información "rosa" o "corazón"

4. Actualidad de espectáculos

5. Sección de gastronomía

Ya que el formato de magazine requiere una puesta en escena propia que se rige por una serie de principios formales y estilísticos desarrollados y testados a lo largo del tiempo por programas de estas características en la televisión generalista, el grupo tuvo que decidir cuál era la puesta en escena y el escenario.

En primer lugar optaron por combinar varios formatos televisivos. Habría un presentador/conductor cuya presencia daría unidad y facilitaría la narración y comprensión. Los contenidos de las distintas secciones se enmarcarían en el formato de la tertulia. En el primer bloque (Actualidad política, económica y social) participarían cuatro personas. Cada una de ellas debería llevar y proponer un tema de actualidad. Ellos eran los responsables de aportar las imágenes y los "totales o declaraciones" que deberían ilustrar el debate, una vez planteado. En la tertulia, cada uno expondría su tema y dejaría abierto el debate para que el resto diera su opinión. En una reunión previa a la emisión del programa, dividieron los papeles y las opiniones, a favor y en contra de cada tema, para asegurarse el contraste de ideas y argumentos. Otra de las decisiones que adoptaron fue no invitar a ningún personaje conocido. Pensaron que si introducían en su tertulia a un periodista famoso o a un político, la sección se convertiría, en el mejor de los casos, en una entrevista. No querían perder el protagonismo de su programa; querían ser los máximos responsables y asumir el papel de "voces autorizadas", para lo que se documentaron apoyándose en datos y ofreciendo opiniones formadas y contrastadas.

Elaboraron una agenda con los temas de actualidad más relevantes del momento. El trabajo lo desarrollaron durante los meses de enero y febrero de 2013. En aquellas fechas, el "caso Bárcenas" ocupaba un primer plano de actualidad en todos los medios de comunicación. Por ejemplo, el 22 de enero, el diario El País titulaba en su primera página: "Rajoy no contestará preguntas sobre Bárcenas hasta el 30 de enero" Cuatro días antes, el 18 de enero, en "meneame.net" se podía leer que "las nuevas revelaciones de la prensa y dudas sobre si el gobierno diseñó la amnistía fiscal para esquivar el escándalo Bárcenas desatan rumores de dimisión". Pero además de la crisis política representada en la corrupción, la crisis económica ocupaba la primera posición en el ranking de las preocupaciones de los españoles. En enero, el número de parados registrados en las oficinas de los servicios públicos de empleo subió en 135.055 desempleados, lo que situó la cifra total de parados en casi cinco millones de personas, un nuevo record del registro. Por último, había un tema que, a principios de años, se hizo con un hueco en la crónica diaria. Los recortes en sanidad se simbolizaron con el cierre nocturno de varios ambulatorios en la comunidad de Castilla La Mancha. La reacción popular consiguió que los medios de comunicación dedicaran 
tiempo y espacio a este asunto. Con este contexto informativo, los temas elegidos por los alumnos para su tertulia de actualidad fueron tres:

1. Papeles de Luis Bárcenas

2. Las cifras del paro

3. Cierre de ambulatorios en Castilla La Mancha

Para ilustrar la tertulia elaboraron colas de imágenes alusivas a cada tema. Además montaron dos vídeos. Un material con el intentaban cambiar el ritmo en dos momentos determinados. El primer vídeo era una encuesta en la calle sobre el tema del desempleo. El segundo fue un pequeño reportaje alusivo a los recortes en la sanidad pública.

Del bloque de sucesos se ocuparon dos personas. En este caso, sólo trataron un tema: la seguridad en las discotecas, pero optaron por abordarlo en profundidad. Unos días antes de realizar este magazine, había tenido lugar en una discoteca de Brasil una tragedia en la que se vieron implicados varios centenares de personas. Empezaron con un vídeo en el que se aportaban todos los datos sobre este suceso y después establecieron una comparación con lo ocurrido en el recinto de Madrid Arena (cinco jóvenes muertas por una avalancha el 1 de noviembre de 2012), lo que les dio pie para hablar sobre las medidas de seguridad que rigen en este tipo de locales. Fueron intercalando grupos de "totales" grabados a jóvenes, en los que estos daban su opinión sobre los sucesos ocurridos y comentaban sus experiencias. Terminaron el bloque con una entrevista a Leticia Prado, abogada especialista en derecho administrativo y derecho penal en la Universidad de Santiago de Compostela, sobre las normas que rigen este tipo de locales de ocio en España.

El tercer bloque estaba dedicado a los temas del espectáculo, los famosos y la moda. La puesta en escena fue similar. Dos personas se encargaron de la presentación y preparación de imágenes. En este caso, los criterios de actualidad respondieron a parámetros estrictamente subjetivos. Tan sólo la actuación, unos días antes, de la cantante Beyonce en la final de Super Bowl, cumplía las mínimas normas exigibles a un hecho noticioso. Los otros dos asuntos fueron diseñados y construidos como un relato informativo para formar el contenido de este bloque.

1. Fran Rivera y Eugenia Martínez de Irujo

2. Actuación de Beyonce en la Super Bowl

3. Últimas creaciones de la diseñadora de joyas Belén Fernández

Para este bloque elaboraron colas alusivas a los temas y editaron un vídeo con Belén Fernández y su taller de joyería.

Finalmente, tres días antes de la "grabación-emisión" del programa, los responsables del equipo nos enviaron uno de los programas cero grabados. Tras el visionado, se les envió un análisis pormenorizado con críticas y sugerencias de posibles cambios. El programa completo se puede ver los siguientes enlaces de nuestra tele- 
visión web Canal Nebrija: http://blogs.nebrija.es/canalnebrija/2013/04/especial-canalnebrija-buenos-dias-nebrija-parte-i/, http://blogs.nebrija.es/canalnebrija/2013/04/ especial-canalnebrija-buenos-dias-nebrija-parte-ii/, http://blogs.nebrija.es/canalnebrija/2013/04/especial-canalnebrija-buenos-dias-nebrija-parte-iii/, http://blogs. nebrija.es/canalnebrija/2013/04/especial-canalnebrija-buenos-dias-nebrija-parte-iv/

El siguiente bloque estuvo dedicado al cine. Uno de los alumnos se encargó de elaborar una crítica con los estrenos de la semana. También elaboraron un vídeo sobre la película "Mama" dirigida por Guillermo del Toro, que en las fechas de elaboración del magazine, tenía una amplia repercusión en las redes sociales.

El programa se cerraba con un microespacio, elaborado por dos personas, dedicado a la gastronomía. Bajo el título "La cocina de Iván" se proponía una receta de fácil elaboración pensada para jóvenes. El formato elegido fue un vídeo, con una posproducción muy cuidada, en el que se enseñaba paso a paso la elaboración del plato propuesto.

A partir de aquí, y durante varios días, el trabajo se subdividió. Cada equipo reasignó tareas a sus miembros. Unos se encargaron de realizar labores de agenda (localización y grabación de personas que formarían parte de sus vídeos), otros se encargaron de editar las colas que ilustrarían sus tertulias. Al tiempo, el director, el editor y el realizador del programa llevaban un control puntual de todas las grabaciones y del cumplimiento del calendario previamente presentado. Una semana después de empezar a trabajar, se convocó a todos los integrantes del equipo a una reunión general en la que se visionaron los brutos de imágenes grabadas y los primeros preeditados. En la reunión se hizo una crítica general de todo lo hecho hasta ese momento. Todos opinaron y todos criticaron el trabajo realizado. Fue una reunión fructífera en la que se sacaron numerosas conclusiones, Sirvió, sobre todo, para corregir el rumbo de algunos trabajos, e incluso abandonar algunas de las ideas previas. Tras esta reunión, los equipos volvieron a separarse y recomenzaron sus trabajos conforme a las nuevas directrices.

La tercera semana de trabajo, el equipo comenzó a realizar números cero o programas ensayo, en los que probaron los movimientos de cámara y los movimientos de los participantes dentro del escenario. Al tiempo, el equipo de dirección y de realización comenzó a diseñar la escenografía del programa. Se empezaron a probar diferentes ubicaciones del plató para la conducción del programa así como para las diferentes secciones. Se introdujeron materiales de decoración como sofás, plantas, mesas... que contribuyeron a dar el ambiente de magazine al programa. A la vez se plantearon los cambios de set y de cámaras necesarios para llevar a cabo el programa en directo.

El equipo 2 estaba formado por 16 alumnos. Eligieron el formato de un magazine late night, al que llamaron "Late Night Show Nebrija". Se trataba de poner en marcha un programa definido en los manuales como un contenedor que abarca desde el clásico talk show hasta los sketches satíricos, a la parodia y la imitación o la crítica política. 
En una discusión general, los alumnos del equipo decidieron dividir su programa en las siguientes secciones: Presentación (monólogo humorístico con toques de actualidad); vídeos que triunfan en la web; entrevista con la cantante Rosa Porta; música en la calle; entrevista con Ramón Arangüena (periodista) y Pablo Motos (presentador de televisión); y una actuación musical de cierre.

En primer lugar, el grupo tuvo que decidir la puesta en escena y el escenario en el que querían llevar a cabo su proyecto. Habría un presentador/conductor del programa, cuya presencia no sería sólo dar continuidad al programa sino que debía ser el protagonista esencial del show. Las características del programa necesitaban que esta persona estuviese dotada de un perfil más próximo al actor o al showman.

Tras una primera tormenta de ideas quedó claro que el programa debía tener un aire humorístico y lúdico, pero que la música debía tener una presencia continua. Necesitaban un cantante con el que pudieran cerrar el late night. Ante la dificultad de encontrar un grupo que acudiera gratis al programa, uno de ellos sugirió que ese papel lo podría hacer una compañera, cantante de una banda semiprofesional. Además, decidieron poner en marcha una sección en la que mezclaban la música con el juego. Consistía en salir a la calle y pedir a la gente que bailara al son de distintas músicas que les iban poniendo.

Introdujeron también dos entrevistas a dos periodistas especializados en humor televisivo. Ramón Arangüena y Pablo Motos.

Una vez dispuesta la escaleta (se adjunta en anexos), llegó la hora de organizar cámaras, set, plató, entradas y salidas de personajes. Es importante destacar el juego de luz que llevaron a cabo entre el primer set del monólogo humorístico de actualidad y el paso al segundo set mediante anuncios de publicidad que también grabaron los propios alumnos. Todo el equipo estuvo muy pendiente de la iluminación y de la complicación añadida que suponía tener un cantante en directo, así como de la entrevista con un conocido periodista televisivo y su implicación en el guión y desarrollo del programa.

http://blogs.nebrija.es/canalnebrija/2013/03/especial-canalnebrija-late-night-show-parte-i/, http://blogs.nebrija.es/canalnebrija/2013/03/especial-canalnebrija-late-night-show-parte-ii/, http://blogs.nebrija.es/canalnebrija/2013/03/especial-canalnebrija-late-night-show-parte-iii/, http://blogs.nebrija.es/canalnebrija/2013/03/ especial-canalnebrija-late-night-show-parte-iv/

\section{La opinión de los alumnos}

Una vez llevada a cabo la experiencia nos pareció que la mejor manera de conocer el éxito o el fracaso de nuestra empresa era preguntar a los propios alumnos. Ellos debían ser los que juzgaran si la metodología experimental había tenido un buen fruto aunando sinergias o por el contrario había resultado un mal proceso de aprendizaje. 
La opiniones fueron claramente favorables, coincidiendo los dos grupos tanto en lo positivo como en el pequeño factor negativo que nos achacaban: la brevedad de la experiencia (33,3\% y $25 \%$ en el grupo 1 y 2 respectivamente). En general, todos valoraban como positiva la experiencia del trabajo en equipo (un $66 \%$ en el grupo 1 y un 43,7 5 en el grupo 2).

Pero claro, el trabajo en equipo supone que no todos los implicados trabajan igual ni tienen el mismo nivel de implicación, por lo que también se reflejaron algunas quejas en cuanto a la falta de colaboración de algunos compañeros (un $20 \%$ y un $6,25 \%$ en el grupo 1 y 2 respectivamente).

Pero lo que nos ha dado la llave para volver a repetir esta actividad conjunta ha sido que la gran mayoría un 73,3\% en el grupo 1 y un $62,2 \%$ en el grupo 2 han valorado la experiencia como personalmente satisfactoria.

\section{Conclusiones}

Uno de los objetivos de nuestra enseñanza es formar a los alumnos para que sean capaces de ejercer el periodismo en programas informativos de todo tipo o formato, $y$ a raíz de los resultados obtenidos creemos que con esta experiencia nuestros nuevos periodistas televisivos son capaces de crear, organizar, dirigir, producir y realizar un programa magazine de televisión. Se ha conseguido desarrollar en ellos una gran capacidad de análisis y de independencia de criterio, perfeccionando las habilidades necesarias para continuar su aprendizaje: autodirigido y autónomo.

Con esta unión de sinergias han aumentado su capacidad para solucionar problemas y realizar tomas de decisiones relacionadas con el tratamiento periodístico de las noticias de diferentes ámbitos dentro de un formato determinado, con condiciones de tiempo limitadas al desarrollarse en directo, y con una alta presión para alcanzar buenos resultados, como se puede ver en los programas.

A la vez, y como ellos mismos han expresado, han logrado trabajar en equipo y dominar la gestión de la diversidad con gran éxito. Han sabido escuchar, debatir y contrastar opiniones e ideas para conseguir un objetivo común, delegando funciones en aquellas personas más adecuadas para cada tarea y aprendiendo unos de otros.

Gracias a la realización en directo del programa han tenido que aplicar las técnicas y procesos de producción y realización en sus diversas fases, tanto desde el punto de vista de la gestión de los recursos técnicos y humanos como de los recursos propios del plató de televisión y de su control. Incluyendo un conocimiento de los recursos tecnológicos disponibles para crear, construir y analizar productos audiovisuales y diseñando estrategias para una comunicación veraz.

Es por todos estos logros, por los que los profesores implicados en esta experiencia consideramos que el proyecto ha tenido éxito y entablamos un compromiso personal y docente para continuar "un poco más allá" en la unión de energías para 
una formación adecuada de los nuevos profesionales del periodismo televisivo. Nos parece que la experiencia docente puesta en marcha tiene en estos momentos una importancia decisiva en la formación de los jóvenes profesionales, pertenecientes a una generación donde prima el individualismo. Este tipo de experiencias les obliga si quieren alcanzar el objetivo propuesto, a ampliar su red de contactos personales, colocando sus ideas, métodos y convicciones en un segundo plano en favor de un objetivo común. Se trata de personas acostumbradas a luchar por ellos y para ellos que con esta iniciativa han tenido que trabajar pensando y, sobre todo, dependiendo del trabajo en equipo.

\section{Bibliografía}

BARROSO, Jaime (2008): Realización audiovisual. Editorial Síntesis. Madrid.

DE MIGUEL, R. (2005). "El grupo de discusión y sus aplicaciones en la investigación de la comunicación masiva". En BERGANZA CONDE, Ma Rosa y RUIZ SAN ROMÁN, José A. (dir.) (2005). Investigar en comunicación. Madrid: Ed Mc Graw Hill. p. 265

Facultad CC de la Comunicación, (2013). Cg7, Memoria Máster Periodismo en Televisión. Madrid: Universidad Nebrija

GONZÁLEZ REQUENA, Jesús (1989): El espectáculo informativo. Akal Comunicación. Madrid.

KATZENBACH, Jon R y SMITH, Douglas K., (1996): Sabiduría de los equipos, Ediciones Díaz Santis, Madrid

KOONTZ, Harold y WEIHRICH, Heinz (1998): Administración una perspectiva global. Editorial Mc Graw Hill, México DF

MAYORAL, Javier (coord.) (2008): Redacción periodística en televisión. Editorial Síntesis. Madrid.

ROBBINS, Stephen, P. (1999): Comportamiento organizacional (Editorial Prentice hall, México DF

SUÁREZ SIAN, Michel D (2007): Dramaturgia audiovisual. Comunicación Social. Sevilla.

UNNE (2010)) Memoria del Máter de Periodismo en Televisión. Facultad de CC de la Comunicación

ZÚÑIGA, Joseba (2006): Realización en televisión. Escuela de cine y vídeo. Andoain

\section{Los autores}

Belén Andueza López. Doctora por la Universidad Complutense de Madrid. Acreditada como "profesor doctor de Universidad Privada" por la ACAP. Licenciada en Ciencias de la Comunicación por la Universidad Complutense de Madrid. Licenciada en Sociología por la UNED. Técnico publicista por el Instituto Mirasierra. Título de 
experto en Avid impartido por el CEV. Profesional de los medios de comunicación como realizadora en TVE y T-5, principalmente en informativos dirigidos por profesionales como Vicente Vallés, Montserrat Domínguez, Juan Pedro Valentín, Ángels Barceló, Hilario Pino, Antonio Lobato... Realizadora de eventos informativos: elecciones legislativas, manifestaciones, conflictos internacionales, Bodas Reales... Elaboración de reportajes educativos para la Comunidad de Madrid. Profesora de másteres de locución y realización televisiva en academias audiovisuales (CEV y CES). Es autora de diversos libros y artículos y colabora con radios de ámbito nacional como Punto Radio o Cadena Ser. En la actualidad es coordinadora de los Másters en Periodismo en Televisión y Periodismo Web de la Universidad Nebrija con Atresmedia e imparte clases en dicha Universidad.

Julián Nieto Redruejo. Doctor por la Universidad Complutense de Madrid. En la actualidad, ocupa el puesto de Gerente de Contenidos Multimedia de A3 Noticias. Con anterioridad, desde 2006 hasta 2011, dirigió el programa matinal Espejo Público, en Antena 3 Televisión. Formó parte de esta cadena desde sus comienzos, en 1989, en donde ha desempeñado numerosos cargos, siempre dentro del área de informativos. A lo largo de estos años ha ocupado, entre otros puestos, el de Director de la Segunda Edición de Noticias (1990); Jefe de la Sección de Nacional (1991-1996); Subdirector de la Primera Edición de Noticias (1997-1998); Jefe de la Sección de Sociedad (2000 y Director del programa semanal de reportajes de Actualidad Espejo Público (20042006). Con anterioridad su experiencia profesional estuvo ligada a la radio. Empezó en la cadena COPE (1973-1975), pasó por Radio Centro y Radio Cadena (1981) y en 1982 formó parte de la redacción fundacional de Antena 3 Radio, donde llegó a ser Redactor Jefe de Noticias. En el área docente es profesor en los Másters en Periodismo en Televisión y Periodismo Web en la Universidad Nebrija. 